\title{
A [re] significação da formação e da prática docente tendo as tecnologias como ferramentas na mediação pedagógica
}

\author{
Valmir da Silva \\ UFSM - Santa Maria, RS - Brasil, E-mail: silvadori12@yahoo.com.br \\ Elvio de Carvalho \\ UFSM - Santa Maria, RS - Brasil, E-mail: helviocarvalho@ hotmail.com \\ Adriana Moreira da Rocha Maciel \\ UFSM - Santa Maria, RS - Brasil, E-mail: adriana.macielrm@gmail.com
}

Resumo: Nosso objetivo é compreender a apropriação das tecnologias na formação docente e na mediação pedagógica da prática do professor no contexto da Escola Básica. Sendo decorrente de pesquisa bibliográfica, fizemos uma incursão pelas políticas públicas para a expansão do ensino superior que visam prioritariamente a formação de profissionais nas licenciaturas do Ensino Básico: (EaD), Educação a Distância, (REUNI) Programa de Apoio aos Planos de Reestruturação e Expansão das Universidades Federais, (UAB) Universidade Aberta do Brasil. Destacando a partir dessas, aspectos acerca do compromisso que a instituição acadêmica e escolar assumem com a formação e a construção do conhecimento tendo as tecnologias como paradigma frente às necessidades educacionais da sociedade. $\mathrm{O}$ estudo indica que a inserção das tecnologias nas atividades acadêmicas e escolares é significativa para estimular o potencial formativo educativo do aluno. Conclui-se, no entanto, que o êxito nessa empreitada depende necessariamente da correlação estratégica entre tecnologia e educação, ambas comprometidas com o processo do ensino-aprendizagem do indivíduo.

Palavras chave: Formação docente. Educação Básica. Tecnologias aplicadas a educação.

\section{[Re] signification of the formation and the teaching practice using technologies as tool in the pedagogical mediation}

Abstract: Our objective is to comprehend the appropriation of technologies in the teaching formation and in the pedagogical mediation of the teacher's practice in the Elementary School context. As a result of literature review, we have made a foray into public policies for the expansion of the higher education that aim primarily the formation of professionals in degree courses of Basic Education: (Ead), Educação a Distância, (REUNI) Programa de Apoio aos Planos de Reestruturação e Expansão das Universidades Federais, (UAB) Universidade Aberta do Brasil. Pointing out from these, aspects about the commitment that the academic and educational institution assume with the formation and the construction of knowledge having the technologies as paradigm to the educational needs of society. The study indicates that the insertion of technologies in academic and educational activities is meaningful to stimulate the learning and formative potential of the student. We concluded, however, that to achieve this objective, it is necessary the strategic correlation between technology and education, both committed to the process of teaching- learning of the self.

Keywords: Teaching formation. Basic Education. Technologies applied to education 


\section{Considerações iniciais}

Considerando que os setores econômicos da sociedade contemporânea, de um modo geral, são fortemente dinamizados pelas inovações tecnológicas, o contexto das instituições formativas educativas não poderia ser diferente. Visto que, as tecnologias se apresentam nesse novo paradigma social como ferramentas mediadoras no processo de aprendizagem e construção do conhecimento. Corresponde metodologicamente, atividades para trabalhar a formação profissional, ressignificar os saberes, comunicar e acessar informações, movimentando assim, possíveis transformações no campo sóciopolítico-cultural e econômico. Justamente por entender que o mundo globalizado tende a se configurar a partir das interações e da produção do conhecimento. Seja em ambientes: acadêmicos, virtuais, e escolares, campos que, valendo-se de tais ferramentas apresentam potencialidades para ampliar os meios de ensino aprendizagem, transformando teorias e práticas na formação educativa.

Essas transformações no campo educacional, atravessadas pelas tecnologias, estão atreladas a alguns fatores: formação inicial e continuada dos professores que vivenciam as tecnologias na teoria e a prática; as atividades educativas no contexto da Educação Básica utilizando-se das tecnologias; as políticas públicas; condições mínimas nas estruturas instituições educativas e formativas; postura crítico-reflexivo do professor; reorganização do currículo das instituições formadoras vinculadas as tecnologias na formação.

Esses fatores na realidade são horizontes visualizados como metas a serem alcançadas gradativamente. Desafios que instigam a capacidade humana na busca de novas alternativas educativas diante dos conflitos sociais e paradigmas culturais. Perspectivas que colocam o indivíduo no centro dos debates e discussões, da mesma forma que são superados pelas constantes buscas pelo conhecimento. Essa busca exige comprometimento político e profissional, visto que, as mudanças de paradigmas são complexas e às vezes contraditórias aos interesses e necessidades comuns da sociedade.

Para fundamentarmos tal discussão, os achados bibliográficos levaram a: (Beloni, 2005), (Falavígna, 2009), (Kenski, 2010), (Barreto, 2010, (Alonso, 2008), (Nóvoa, 2007), autores de referência no cenário da temática em questão. Nóvoa (2007) anuncia o surgimento de um novo sujeito capaz de aprender através da interação tecnológica, sendo necessário que as instituições de ensino se adaptem humanamente e tecnologicamente para atender esse novo sujeito. Por sua vez, Kenski (2010) analisa a transição social para uma nova postura no modo de fazer e trabalhar a educação a partir das tecnologias. Falavigna (2009) analisa o uso de multimeios e tecnologias digitais no processo ensino-aprendizagem. Barreto (2004) argumenta que as Tecnologias da Informação e Comunicação devem justamente ser compreendidas como fator de atravessamento na formação de professores, deslocando sentidos e territórios. Desse modo, a intensificação do uso das ferramentas tecnológicas na formação de professores e na Educação Básica pode ser compreendida como apropriação cultural pedagógico das novas tecnológicas na educação.

No cotidiano acadêmico e escolar são comuns certos entendimentos sobre o uso das tecnologias na educação. Alguns até contraditórios, haja vista, diferentes concepções: "ensino assistido por computador", no qual o computador é a única fonte de informação; "alfabetização digital", a introdução e o uso técnico da informática na educação. A proposta de Ponte (2000, p. 71) concebe o uso das tecnologias como "ferramentas educacionais". Para Alonso (2008, p. 762) esta última concepção traz, "a ideia das tecnologias como recursos e instrumentos na e da aprendizagem". 
Nessa compreensão, entende-se a importância de uma ação crítico-reflexiva tanto do formador quanto do professor ao fazer uso das tecnologias no processo formativo educativo. O qual passa a ser compreendido, nesse novo paradigma educacional, como uma alternativa para se levar adiante a intencionalidade da democratização do ensino no Brasil. Desse modo, é pertinente discutir a [re] significação da formação docente e as metodologias para o ensino aprendizado na Educação Básica, diante do discurso anunciado pelas políticas públicas, assim como a prática pedagógica frente às tecnologias. Visualizando assim, possíveis alternativas mobilizadoras para atender as necessidades educacionais comuns da sociedade.

\title{
Estratégias para formação de professores para a Educação Básica
}

No Brasil, o acesso ao conhecimento e aos níveis mais elevados de educação é garantido na Constituição Federal em seu Art. 208: Inciso V. (BRASIL, 1988). Tal propósito tende a garantir o desenvolvimento de uma sociedade soberana, justa e democrática, sendo a educação o fator basilar. Nesse sentido, o acesso público e gratuito à Educação Superior sempre esteve restrita aos espaços urbanos, predominantemente nas capitais das unidades federativas, com raras exceções (Santa Maria e Pelotas na Região Sul, por exemplo, até pouco tempo eram as únicas cidades do interior sulriograndense a ter universidade federal). No entanto, tem-se observado o movimento nacional em direção à expansão e interiorização da Educação Superior. Fenômeno que abre significativas discussões no espaço acadêmico para compreender essa nova realidade do ensino-aprendizagem para a formação. Um contexto marcado por transformações tecnologias no campo educativo, assim como dos programas de expansão do ensino no Brasil. A isso, compreende-se que:

\begin{abstract}
A Universidade como contexto institucional é um cenário complexo e multidimensional no qual repercutem as mudanças sociais e influências de todo tipo. Consequentemente, a gestão universitária é desafiada a transitar em um duplo espaço de referência ao traçar políticas e estratégias rumo à melhoria da qualidade de suas ações, compreendendo o quanto se encontra imbricado o mundo universitário interno e o espaço externo. No Brasil, os últimos anos têm sido movimentados pela ideia de expansão e interiorização da Educação Superior. (MACIEL, 2011, p. 223).
\end{abstract}

Desde 2007, o REUNI, Programa de Apoio aos Planos de Reestruturação e Expansão das Universidades Federais ${ }^{1}$, instituído pelo Decreto ${ }^{\circ} 6.096$, de 24 de abril de 2007, vem sendo desenvolvido. No qual uma das ações previstas no Plano de Desenvolvimento da Educação (PDE), é estimular as Instituições Federais de Ensino Superior (IFES) para a proposição de projetos expansionistas e inovadores, rompendo inclusive com os desenhos curriculares tradicionais ${ }^{2}$.

Por este viés das políticas públicas, o PDE é uma política pública que incentiva o diálogo entre professores da Educação Superior e da Educação Básica, tendo como horizonte a produção de conhecimento e mudanças qualitativas no Sistema Escolar Público. Um dos principais pontos dessa política refere-se à formação de professores para a Educação Básica, prevendo avanços na carreira e na formação, demonstrando

\footnotetext{
${ }^{1}$ Disponível em: <http://reuni.mec.gov.br/>

${ }^{2}$ Nesse sentido, a Unidade Descentralizada de Silveira Martins, UDESSM, projeto da UFSM na Proposta do REUNI, tem estrutura administrativa diferenciada e o seu currículo foi desenhado com base em projetos de ensino, pesquisa e extensão, de forma integrada. Disponível em: <http://www.ufsm.br/udessm/admin/uploads/Projeto\%20Institucional\%20da\%20UDESSM.pdf>.
} 
preocupação com a capacitação permanente dos professores e com o aprendizado do sujeito. (BRASIL, 2007).

Assim sendo, o REUNI canaliza o objetivo de ampliar o acesso e a permanência na Educação Superior, prevendo a adoção de uma série de medidas para retomar o crescimento do ensino superior público, promovendo a expansão física, acadêmica e pedagógica. Tais iniciativas possibilitaram uma expansão emergente do ensino superior nas diversas regiões do Brasil.

O Decreto $\mathrm{n}^{\circ} .5 .622 / 05^{3}$ o qual regulamenta o art. 80 da Lei de Diretrizes e Bases da Educação Nacional, ño 9.394/96 ${ }^{4}$ caracteriza a Educação a Distância como modalidade de ensino. Essa modalidade possibilita a mediação pedagógica em ambientes virtuais de ensino aprendizagem, utilizando-se as Tecnologias de Informação e Comunicação para viabilizar o acesso à formação, onde "professores e alunos interatuam no processo de desenvolvimento de seus conhecimentos a partir da interatividade tecnológica em lugares e tempos diferentes". (BRASIL, 2005, S/P). É criada então, a Universidade Aberta do Brasil - UAB, um Programa do Ministério da Educação que atua na organização de parcerias para oferta de cursos de graduação e pós-graduação a distância. (BRASIL, 2006).

Nessa modalidade educacional, a probabilidade do professor formar-se numa cultura tecnológica, ampliando os horizontes metodológicos de sua prática pedagógica, a partir do uso dessas novas ferramentas, favorece o professor, a desenvolver em sala de aula, atividades mediadas pelas tecnologias. Essa perspectiva torna-se ainda mais ampla a partir da modalidade a distância como possibilidade formativa educativa em rede. Percebe-se, pois, no discurso do Ex-Ministro da Educação Fernando Haddad, quando se referia, em fala, a essas novas estratégias para a educação. Afirma ele, que as políticas públicas vêm estabelecendo medidas para universalização do acesso ao ensino superior e a formação de professores. (HADDAD, 2006, pp.7-9). Nesse particular, tende-se a considerar que a modalidade/EaD pode justamente ter impactos significativos na formação inicial e desencadear uma cultura de se fazer e dar sentido ao desenvolvimento dos saberes e da construção do conhecimento mediados pelas ferramentas tecnologias.

Por este viés, na já conhecida sociedade da informação e comunicação, na qual cada vez mais a formação docente se faz necessária, por considerar que o aluno traz para o contexto escolar, uma gama de conhecimentos desenvolvidos a partir das interações com as diversas ferramentas tecnológicas do seu cotidiano. Nesse sentido, é fundamental levar em consideração as tendências da mídia-educação aplicadas à educação. Belloni (2005) argumenta que:

Do livro e do quadro de giz à sala de aula informatizada e online a escola vem dando saltos qualitativos, sofrendo transformações que levam de roldão um professor mais ou menos perplexo, que se sente muitas vezes despreparado e inseguro frente ao enorme desafio que representa a incorporação das TIC no cotidiano escolar. Talvez sejamos ainda os mesmos educadores, mas certamente nossos alunos já não são mais os mesmos [...]. Abre-se um novo e vasto campo de pesquisa, que diz respeito aos "novos modos de aprendizagem mediatizada". Este Novo campo, necessariamente

\footnotetext{
${ }^{3}$ Disponível em: < http://portal.mec.gov.br/seed/arquivos/pdf/dec 5622.pdf $>$.

${ }^{4}$ Art. 80 da LDBN n.9394/96: "O Poder Público incentivará o desenvolvimento e a veiculação de programas de ensino a distância, em todos os níveis e modalidades de ensino, e de educação continuada". Disponível em: 〈http://www.planalto.gov.br/ccivil_03/Leis/L9394.htm>.
} 
interdisciplinar, tem que considerar os dois principais componentes dessa nova pedagogia: a utilização cada vez maior das tecnologias de produção, estocagem de transmissão de informação, por um lado, e, por outro, o redimensionamento do papel do professor. Papel este que ao que tudo indica, tende a ser cada vez mais mediatizado. (BELLONI, 2005, PP. 27, 29).

A isso, é coerente dizer que professores e alunos, podem experimentar novas possibilidades de aprendizagem e de [trans] formação no processo de construção do conhecimento. Essas transformações culturais estão alicerçadas na interatividade, sejam presenciais e ou virtuais. Porém, sendo as tecnologias uma realidade para alguns profissionais da modalidade Educação a Distância, ainda é uma incógnita para muitos professores. As mudanças no conceito de formação do profissional da educação para o século XXI devem justamente acompanhar as tendências de uma sociedade cada vez mais informatizada e virtual, sem perder o vínculo com o presencial e o mundo real.

Porém, na condição de indivíduos presentes nas discussões políticas e sociais, no que se referem às trajetórias, lutas e conquistas para a educação no Brasil, precisamos compreender que grande parte das estratégias políticas deve-se às demandas e necessidades sociais. E essas, conduzidas pelas mudanças econômicas dos últimos tempos, estabelecendo assim, um novo ritmo à sociedade, o ritmo do progresso. Nesse sentido, é conveniente para o sistema legislativo que as instituições educativas se adaptem às novas necessidades e realidades sócio-político cultural. A isso, Alonso (2008) argumenta que:

\footnotetext{
Apesar de se alardear o novo - a sociedade da informação e do conhecimento -, onde, presumidamente, não só consumiríamos, mas produziríamos informações, os professores, como "ponta" da inovação, terão muito pouco que falar sobre sua formação. Haverá quem os oriente sobre quais competências profissionais se deseja para que o sistema público de ensino seja transformado. (ALONSO, 2008, p.762)
}

Apontamentos que desvelam a intenção política de governo quanto ao direcionamento da função das instituições formativas educativas da sociedade contemporânea. Uma perspectiva imbricada na incumbência de responder, com alguma rapidez, à incorporação de mecanismos aparentemente flexíveis às reestruturações curriculares e metodológicas, tendo como pauta recorrente, neste estudo, o uso de tecnologias em rede na formação de novos profissionais para o Ensino Básico. Tal fenômeno vem repercutindo em mudanças efetivas no sistema educativo. Diante de tais fatos, cabe à comunidade acadêmica e escolar, se reorganizar em torno dessas mudanças e fazer a diferença a partir de uma prática transformadora.

\section{O compromisso acadêmico e escolar no processo da formação educativa}

A princípio, grande parte das iniciativas públicas tem como foco proteger os interesses do mercado de trabalho e do desenvolvimento econômico. Razões estas, que acabam demarcando mudanças superficiais no campo educacional. Por este viés, o papel das tecnologias pode se reduzir a uma estratégia expansionista, caso não seja entendida de modo responsável pelas instituições formativas educativas. Negligenciar tal perspectiva é enveredar para um caminho de mudanças pouco sólidas. Não atinge o cerne da problemática educacional, enraizada na problemática da qualidade formativa.

A partir de uma perspectiva crítica, Crochik (2003) argumenta que as tecnologias surgiram da necessidade da indústria e do capital. A televisão nasce na esfera do entretenimento, configurando-se como um aspecto problemático quando 
proposta para a educação, pois confere um caráter de Indústria Cultural ${ }^{5}$. Segundo o autor seria ingênuo pensar que as novas tecnologias educacionais podem ser responsáveis pela racionalização da educação. Essa racionalização já está presente e continua sendo apresentada na didática moderna e na educação de massa. Da mesma forma que as tecnologias são desenvolvidas para a racionalização da indústria do capital, essa lógica, logo também deve fazer parte do sistema educacional. Por isso, o lamentável conceito contemporâneo de educação voltada para atender os interesses do mercado de trabalho.

Nesse contexto de complexidades, existe, no entanto, um enredamento onde convive o humano, a política, a economia, o conhecimento e as tecnologias, nas quais se reconhece a necessidade de se fazer compreender e desenvolver qualidades de sujeito ensinante, aprendente, cooperativo e autônomo. Papel mediador obviamente atribuído à instituição acadêmica e escolar. Falavigna (2009) apresenta argumentos, a partir das perspectivas sociais, tendo as instituições de ensino como parâmetro ao avaliar o caráter curricular que tais instituições assumem diante das tecnologias digitais e associadas no contexto formativo e educativo. Em seus estudos, a autora afirma que os recursos tecnológicos podem melhorar o ensino e a aprendizagem dos alunos, por serem ferramentas didático-pedagógicas eficazes e fundamentais para uma formação coerente com tempos, onde a informação passa ser instantânea e as imagens um recurso visual significativo na compreensão das informações. Os recursos tecnológicos melhoram o interesse e a motivação dos alunos, facilitando e qualificando o desempenho acadêmico e escolar, da mesma forma que, enaltece a imagem pública da instituição.

Na compreensão de Kenski (2010) vive-se um momento de plena transição social, mudanças que se caracterizam por uma nova postura na forma de pensar e de fazer educação. Tal paradigma projeta um novo conceito didático e metodológico nos ambientes educacionais. Isso implica assumir uma nova postura crítico-reflexiva diante das ferramentas tecnológicas de comunicação e informação, adaptando-as de maneira coerente aos conteúdos pedagógicos.

\begin{abstract}
Em educação, as tecnologias eletrônicas de comunicação funcionam como importantes auxiliares. [...] As tecnologias digitais de comunicação e de informação, sobretudo o computador e o acesso à internet, começam a participar das atividades de ensino realizadas nas escolas brasileiras de todos os níveis. Em algumas elas vem pela conscientização da importância educativa que esse novo meio possibilita. Em outras, são adaptadas pela pressão externa da sociedade, dos pais e a comunidade. Na maioria das instituições, no entanto, elas são impostas, como estratégia comercial e política sem a adequada reestruturação administrativa, sem reflexão e sem a devida preparação do quadro de profissionais que ali atuam. (KENSKI, 2010, PP. 69, 70).
\end{abstract}

Barreto (2010) apresenta uma expectativa importante sobre esse ponto de vista. Indica o uso das tecnologias no processo formativo docente, assim como, pelas escolas nas atividades de aprendizagem. Para isso, precisam ressignificar-se didaticamente e metodologicamente a partir do momento em que se apropriam delas como possibilidades pedagógicas na prática do professor.

Frente a este cenário de mudanças, configura-se uma educação ainda presa ao passado pelas suas práticas no espaço escolar. Práticas que possivelmente pouco acompanham as expectativas dos estudantes com relação às novas propostas

\footnotetext{
5 A indústria cultural, segundo Adorno e Horkheimer, possui padrões que se repetem com a intenção de formar uma estética ou percepção comum voltada ao consumismo. (ADORNO E HORKHEIMER, 1971).
} 
metodológicas de ensino-aprendizagem, coerentes com o paradigma cultural contemporâneo. A partir dos estudos de Plou (2007, p. 13) pode-se entender que novas didáticas são necessárias. "Não mais minimalistas", ou seja, com uso mínimo de ferramentas para desenvolver a formação e a construção do conhecimento, mas estabelecendo uma relação ampla e significativa com as tecnologias.

Refletir sobre essas novas possibilidades pode fortalecer o lugar social do professor e a sua capacidade em lidar com as situações peculiares do cotidiano acadêmico e escolar. No entanto, nenhum projeto inovador tem valor se as novas ferramentas forem visualizadas apenas como meio para facilitar a prática docente. Dar sentido e significado pedagógico a ação docente é um compromisso muito sério frente à realidade tecnológica presente em grande parte do contexto acadêmico e escolar. Com relação a isto, Nóvoa diz que:

\begin{abstract}
No seu livro "A Galáxia Internet", Manuel Castells explica que as novas tecnologias obrigam a repensar grande parte do que foi a educação durante a era industrial. E acrescenta que, antes de pensarmos as mudanças tecnológicas na reestruturação das escolas ou mesmo na formação de professores, deveríamos compreender a necessidade de uma nova pedagogia baseada na interatividade, na personalização e no desenvolvimento da capacidade autônoma para aprender e para pensar. Esta nova pedagogia põe em questão convicções fortemente arraigadas na cultura docente, explicando, por exemplo, que nem sempre se aprende do mais simples para o complexo ou do mais concreto para o mais abstrato. Em educação, as tecnologias devem inserir-se nesta busca de novos processos pedagógicos que reforcem o papel do professor e sua capacidade para responder às situações imprevisíveis do dia-a-dia escolar (NÓVOA, 2007, p. 30).
\end{abstract}

Um novo indivíduo emerge desse contexto de mudanças culturais e tecnológicas. Um ser humano autônomo, capaz de aprender a partir da interatividade, do compartilhamento, da criatividade, da invenção de novos processos pedagógicos, capaz de novas apropriações do saber. Crochik (2003) argumenta que existe uma grande diferença entre ensinar os alunos a usar o computador e manusear diferentes tecnologias a fim de que transmitam informações. Essas informações, que são culturais, quando transmitidas, primeiramente são filtradas pela racionalidade do meio técnico, o indivíduo recebe-as já selecionadas ou manipuladas pelo sistema. Assim, uma das funções do professor é contribuir para que o aluno identifique essas questões e possa buscar a partir das tecnologias digitais, como a internet, nas redes sociais, informações que esclareçam certas dúvidas e o ajude a formar opiniões.

Em outro momento, Crochik (2003) lembra que a proposta do uso do computador, por exemplo, em sala de aula, pode representar-se na intenção do professor, como fator motivacional, a fim de justificar a falta de interesse aos conteúdos. Justifica essa perspectiva a partir da concepção de que a instituição de ensino como está posta com seu currículo engessado e conteudista, não consegue atrair a atenção dos alunos, justamente por sua aridez e desvinculação com a realidade social dos indivíduos.

Mais uma vez, compreendem-se os novos cenários educacionais, exigindo de seus protagonistas que interajam com novas coreografias didáticas. Para Zabalza (2006) as coreografias didáticas configuram cenas em que interatuam ensino e aprendizagem, pressupondo-se que o ciberespaço pode ser percebido como um espaço potencialmente educativo. Também possibilita oferecer informação para a aquisição e 0 desenvolvimento de competências docentes e discentes. Isto porque os processos de aprendizagem dos estudantes mantêm uma forte relação com os métodos de ensino dos 
professores e porque existe uma interconexão entre as estratégias de ensino que o professor utiliza e a forma como os alunos aprendem. Contraditoriamente a esta ideia,

\begin{abstract}
Alunos e professores todos os dias levam telefones celulares para a sala de aula. Os filmes, as músicas, os jogos, as relações interpessoais mediadas pelos protocolos da rede (física, lógica e social), estão presentes nas salas de aula, nos banheiros, nos corredores, nos pátios (...). Só não estão muito presentes, ainda, na didática dos professores, nos materiais didáticos e nas aulas de prática de ensino das universidades que formam professores. (ANTONIO, 2010, on line)
\end{abstract}

A rotina acadêmica e escolar aos poucos vai sendo confrontada com novos cenários e coreografias didáticas (ZABALZA, 2006), à medida que se desenvolvem projetos, estudos e novos conhecimentos. Os processos de ensinar e aprender vão sendo compreendidos frente à relação entre o humano e o mundo tecnológico por ele desenvolvido.

A escola hoje lida com nativos digitais $^{6}$. Isto é um fato. Novas relações são estabelecidas com o conhecimento, utilizando instrumentos de mediação e interação nos espaços virtuais e presenciais. Configuram-se possibilidades para práticas pedagógicas inovadoras, demonstrando que o uso das tecnologias como ferramentas na educação pode promover a aprendizagem. Elas são mais atraentes e podem promover uma aprendizagem ativa, em que o indivíduo aprende interatuando. Nesse sentido, o formador/professor que tem em sua formação experiências dessa cultura, possivelmente atuará numa perspectiva crítico-reflexiva, ampliando assim, os horizontes do processo do ensino-aprendizagem.

\title{
Considerações finais
}

A educação para o século XXI está sendo marcada por paradigmas tecnológicos e possivelmente seja o desafio mais instigante que as instituições formativas educativas e seus profissionais terão que enfrentar nos próximos tempos. Se pensarmos que a educação deve justamente acompanhar o ritmo e as necessidades da sociedade, logo se percebe que muitas coisas ainda precisam ser [re] feitas, pois os indivíduos fora do contexto institucional educativo, já convivem com as informações em tempo real em diferentes tipos de tecnologias.

O que estamos experienciando hoje é a perspectiva de interação em ambientes virtuais de ensino-aprendizagem no contexto da Educação a Distância e, mais especificamente, na formação inicial e continuada de professores. Não significa necessariamente uma ideia de formação individual, em que o indivíduo fique e se sinta inteiramente isolado no processo de construção do conhecimento. O profissional em formação permanece interligado numa espécie de teia de cooperação, determinada por articulações estruturais da instituição de ensino, sejam elas, humanas, curriculares, metodológicas ou tecnológicas.

A partir dessas expectativas, se configura o desenvolvimento de práticas sociais inovadoras na área da formação e do ensino, podendo resultar em transformações significativas no ambiente social, acadêmico e escolar. Com isso, espera-se criar um fluxo constante de produção de conhecimentos, podendo transcender os muros da

\footnotetext{
${ }^{6} \mathrm{O}$ termo Nativo digital, aplicado em contextos como a educação, refere-se às pessoas que nasceram e cresceram com as tecnologias digitais do Século XXI presentes em sua vida e influenciando as suas aprendizagens. (PRENSKY, 2001).
} 
instituição de ensino, seja ela presencial ou virtual, possibilitando ao indivíduo reconhecer outras formas de aprender e ensinar que não sejam somente àquelas instituídas na sua experiência estudantil, ao longo do seu percurso escolar.

A reflexão a respeito da [re] significação da formação de professores e da prática pedagógica no Ensino Básico, utilizando-se das tecnologias como ferramentas, deve justamente potencializar a compreensão sobre a possibilidade da mediação dessas na ação docente. Nesse momento histórico de busca por alternativas e possibilidades para a educação, a cultura tecnológica media à construção do conhecimento, uma vez que anuncia novos modos de relação com o saber, com o trabalho e com o próprio existir do ser humano na busca da sua autonomia.

Nesse sentido, os caminhos e descaminhos dos processos que marcam as políticas educacionais e suas estratégias públicas para a educação no Brasil, apontam para a possibilidade das instituições de ensino desenvolver projetos educacionais que dêem conta das necessidades da sociedade contemporânea. Tanto na formação inicial e continuada de professores quanto no processo de ensino e aprendizado dos alunos do Ensino Básico.

Porém, é coerente sublinhar que a transformação e a qualidade do ensino dependem, em grande parte, de uma prática pedagógica comprometida. As tecnologias não se apresentam como um pacote de milagres que traz mudanças instantâneas na prática do professor e no modo de aprender dos seus alunos, e com isso, a solução dos problemas de ensino e aprendizagem das instituições educacionais. Pelo contrário, as instituições de ensino devem incorporá-las em suas práticas de forma adequada e coerente, como meio e possibilidades de melhorar na qualidade da educação e das relações pedagógicas no processo de aprendizagem.

As inquietações aqui desenhadas podem se apresentar como questões investigativas, caracterizando-se também como possíveis problematizações para diferentes intervenções no contexto da educação, da formação inicial e continuada de professores. Apropriar-se das tecnologias no campo educacional exige, não só uma reestruturação na organização do sistema educativo, como também, uma ressignificação da prática pedagógica.

Desse modo, a correlação estratégica entre tecnologia e educação indica uma conexão em que os dois pólos ganham ao se fortalecerem imbricadamente. Por um lado, os meios de comunicação permitem dinamizar, facilitar e sustentar uma aprendizagem. E pelo outro, o sujeito tem a possibilidade de interagir, desafiar, desenvolver, repensar e recriar as potencialidades educativas dos meios de informação e comunicação. Fazendo dessas possibilidades, um caminho mais instigante e feliz nas escolhas e realizações conscientes, sejam elas, pessoal e/ou profissional.

\section{REFERÊNCIAS}

ADORNO, Theodor W. Teoria de la Seudocultura. In: HORKHEIMER, M. Madri: Taurus Ediciones, 1971.

ALONSO, K. M. Tecnologias da informação e comunicação e formação de professores: sobre rede e escolas. Revista Educação e Sociedade, Campinas, vol. 29, n. 104 - Especial, p. 747-768, out. 2008 747. Disponível em <http://www.scielo.br/pdf/es/v29n104/a0629104.pdf>. [Acessado em 10/02/2012].

ANTONIO, J. Carlos. O uso pedagógico da Sala de Informática da escola. Professor Digital, SBO, 08 maio 2010. Disponível em: < 
http://professordigital.wordpress.com/2010/05/08/o-uso-pedagogico-da-sala-deinformatica-da-escola/ />. Acesso em 11/02/2012.

BARRETO, R. G. Tecnologia e educação: trabalho e formação docente. Educação \& Sociedade, Campinas, v. 25, n. 89, p. 1181-1201, set./dez. 2010.

BELLONI, Maria Luiza. O que é mídia-educação? 2a Ed. Campinas: Autores Associados, 2005.

BRASIL. Ministério da Educação e Cultura. O Plano de Desenvolvimento da Educação: razões, princípios e programas. Brasília, 2007.

BRASIL. Decreto ${ }^{\circ}$. 5.622/05 de 19 de dezembro de 2005. Dispõe sobre o reconhecimento da EaD como modalidade educacional, MEC, Brasília, 2005.

BRASIL. Constituição da República Federativa do Brasil. Brasília, DF, 1988.

BRASIL. Decreto ${ }^{\circ}$. 5.800, de 08 de junho de 2006._Dispõe sobre o Sistema Universidade Aberta do Brasil - UAB, Presidência da República Casa Civil. Subchefia para Assuntos Jurídicos. Brasília, 2006.

CROCHIK, José León. Teoria crítica e novas tecnologias da educação. In: Tecnologia cultural e formação... Ainda. Auschwitz. (Org.) PUCCI, B.; LASTÓRIA, L. A. C. N.; COSTA, B. C. G. São Paulo: Cortez, 2003.

FALAVIGNA, Gladis. Inovações centradas na multimídia: repercussões no processo ensino-aprendizagem. Porto Alegre: Edipuc, 2009.

HADDAD, F. Prefácio. In: Secretaria de Educação A Distância (Org.). Desafios da educação a distância na formação de professores. Brasília, DF: SEED, 2006, pp.7-9.

KENSKI, Vani Moreira. Tecnologias e ensino presencial e a distância. $9^{a} \mathrm{Ed}$. Campinas: Papirus, 2010.

MACIEL, A. M. R. A aprendizagem docente nos anos iniciais da profissão: construindo redes de formação na educação superior. In: Qualidade da Educação Superior: a universidade como lugar de formação.1 ed. Porto Alegre : EDIPUCRS, 2011, v.2, p. 213-231. [Série Qualidade da Educação Superior]. Disponível em: <http://www3.pucrs.br/portal/page/portal/edipucrs/Capa/PubEletrSeries $>$.

NÓVOA, Antônio. Formação de Professores. Revista Aprendizagem. Ano 1 nº 2 , setembro/outubro. São Paulo: Melo, 2007.

PLOU, Dafne. VIEIRA, Vera. Mulher e Tecnologias - a virtualidade como espaço transformador das relações de gênero. SP. Rede Mulher de Educação. 2007.

PONTE, J.P. Tecnologias de informação e comunicação na formação de professores: que desafios? Revista Iberoamericana de Educación, Madrid, n. 24, p. 6390, sep./dec. 2000.

ZABALZA, M. A. Uma nova didática para o ensino universitário: respondendo ao desafio do espaço europeu de ensino superior. In: Sessão Solene comemorativa do Dia da Universidade - $95^{\circ}$ aniversário da Universidade do Porto. Porto: Faculdade de Psicologia e Ciências da Educação, 2006. 